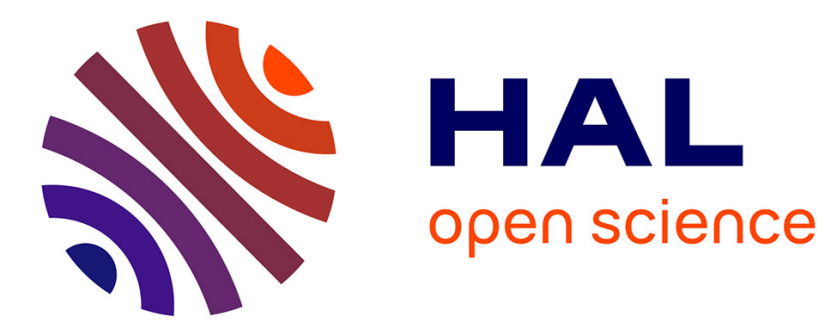

\title{
Determination of Chloramphenicol Residues in Crustaceans: Preparation and Evaluation of a Proficiency Test in Germany
}

Joachim Polzer, Rudolf Hackenberg, Carolin Stachel, Petra Gowik

\section{- To cite this version:}

Joachim Polzer, Rudolf Hackenberg, Carolin Stachel, Petra Gowik. Determination of Chloramphenicol Residues in Crustaceans: Preparation and Evaluation of a Proficiency Test in Germany. Food Additives and Contaminants, 2006, 23 (11), pp.1132-1140. 10.1080/02652030600743805 . hal-00577480

\author{
HAL Id: hal-00577480 \\ https://hal.science/hal-00577480
}

Submitted on 17 Mar 2011

HAL is a multi-disciplinary open access archive for the deposit and dissemination of scientific research documents, whether they are published or not. The documents may come from teaching and research institutions in France or abroad, or from public or private research centers.
L'archive ouverte pluridisciplinaire $\mathbf{H A L}$, est destinée au dépôt et à la diffusion de documents scientifiques de niveau recherche, publiés ou non, émanant des établissements d'enseignement et de recherche français ou étrangers, des laboratoires publics ou privés. 


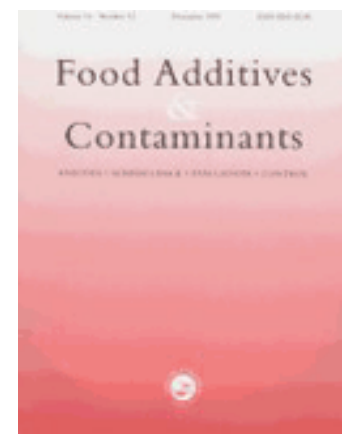

\section{Determination of Chloramphenicol Residues in Crustaceans: Preparation and Evaluation of a Proficiency Test in Germany}

\begin{tabular}{|r|l|}
\hline Journal: & Food Additives and Contaminants \\
\hline Manuscript ID: & TFAC-2005-372.R1 \\
\hline Manuscript Type: & Original Research Paper \\
\hline Author: & 27-Mar-2006 \\
\hline Complete List of Authors: & $\begin{array}{l}\text { Polzer, Joachim; Federal Office of Consumer Protection and Food } \\
\text { Safety, EU and National Reference LAboratory for Residues } \\
\text { Hackenberg, Rudolf } \\
\text { Stachel, Carolin } \\
\text { Gowik, Petra; Federal Office of Consumer Protection and Food } \\
\text { Safety, EU and National Reference LAboratory for Residues }\end{array}$ \\
\hline Methods/Techniques: & Proficiency testing, Chromatography - GC/MS, In-house validation \\
\hline Additives/Contaminants: & Veterinary drug residues - chloramphenicol \\
\hline Food Types: & Animal products - meat \\
\hline & \\
\hline
\end{tabular}

\section{SCHOLARONE Manuscripts}




\title{
Determination of Chloramphenicol Residues in Crustaceans: Preparation and Evaluation of a Proficiency Test in Germany
}

\author{
J. Polzer, R. Hackenberg, C. Stachel and P. Gowik \\ EU and National Reference Laboratory for Residues in the \\ Federal Institute for Consumer Safety and Public Health (BVL) \\ Diedersdorfer Weg 1, D-12277 Berlin, Germany
}




\begin{abstract}
Chloramphenicol (CAP) is banned for use in food producing animals and is thus controlled on the basis of the National Residue Control Plans in the European Union. Due to the current problems with residues of CAP in shrimps, crayfish and prawns, a sensitive $\mathrm{GC} / \mathrm{NCl} / \mathrm{MS}$ method was optimised and in-house validated. The validation study resulted in a decision limit $\left(\mathrm{CC}_{\alpha}\right)$ of $0.07 \mu \mathrm{g} / \mathrm{kg}$, a recovery of $95 \%$ and a within-laboratory reproducibility of $9 \%$. The method was used for preparing a proficiency test in order to assess the quality of residue control in Germany. The proficiency test involved analysis of five samples and the results were very satisfactory. The reproducibility standard deviation for five samples ranged from 17 to $24 \%$, and the median concentrations lay between 0.43 and $0.51 \mu \mathrm{g} / \mathrm{kg}$ CAP. These values are clearly below the corresponding Horwitz standard deviation of about $50 \%$. From the study it can be concluded that there are - irrespective of the method applied - well established and properly working analytical procedures for the control of CAP around the MRPL of $0.3 \mu \mathrm{g} / \mathrm{kg}$.
\end{abstract}

Keywords: Chloramphenicol, proficiency testing, shrimps, validation, GC-NCI-MS, MRPL, residue control 


\section{Introduction:}

Chloramphenicol (CAP) is banned for use in food producing animals in the European Union (Annex IV of Council Regulation 2377/90/EC) and is thus to be controlled on the basis of the National Residue Control Plans (Council Directive 96/23/EC). Even though it is an effective broad-spectrum antibiotic, its use was forbidden in the European Union in 1994 due to severe side effects, as e.g. aplastic anemia. Since these toxic effects are not dose dependent, a no effect level could not be established and consequently a zero tolerance level was set for CAP in food.

In 2003, with Commission Decision 2003/181/EC, a minimum required performance limit (MRPL) of $0.3 \mu \mathrm{g} / \mathrm{kg}$ for residues of CAP in different matrices, as e.g. muscle and aquacultures, was fixed. The MRPL was introduced with Commission Decision 2002/657 EC and was meant as the "minimum content of an analyte in the sample, which at least has to be detected and confirmed". The aim of the MRPL was a harmonisation of the control of substances for which no MRL could be established. Since the level of the MRPL is not based on a risk assessment but on an assessment of a residue level which could be controlled by a majority of laboratories in residue control, it is clear that lower control limits are possible and welcome in order to meet scientific progress (as far as the method is validated according to the requirements of Commission Decision 2002/657 EC). This paper describes a sensitive GC/NCI/MS method, which is able to achieve decision limits for CAP below $0.1 \mu \mathrm{g} / \mathrm{kg}$ and which is validated according to this decision using the in-house validation approach (Jülicher et al. 1998) by applying a statistical software ("InterVal'TM", quo data Itd., Dresden, Germany). 
This method was developed because of recent problems with residues of CAP in import samples of shrimps and crayfish. According to these recent findings, also the number of publications dealing with the analysis of CAP has increased significantly since 2003. Meanwhile a number of different methods is available, which allows the control of the actual MRPL (e.g. Rupp et al. 2005, Peng et al. 2005, Penney et al. 2005, Santos et al. 2005, Hammack et al .2003, Ramos et al. 2003, Mottier et al. 2003).

One of the tasks a National Reference Laboratory should fulfil according to Council Regulation 882/2004/EC and Commission Decision 96/23/EC is to organise comparative tests between official national laboratories. In order to meet these requirements, proficiency test material was prepared and tested for homogeneity and stability by applying the above mentioned method. Using this material (five different test samples from four different laboratory samples), a proficiency test according to the International Harmonised Protocol for the Proficiency Testing of (Chemical) Analytical Laboratories (Thompson and Wood 1993, IHPPT) was organised and the official residue control laboratories in Germany were offered to participate. The NRL took part in this study as one of the participants. The second part of the paper gives the results of this proficiency test. Additionally the potential influence of parameters on the analytical results is evaluated in detail. This is done on the basis of the information about the various methods applied by the participating laboratories.

\section{Materials and methods}

GC-MS (negative chemical ionisation) method

Materials and instrumentation 
Standards were obtained from Sigma Aldrich (CAP, >99 \%) and from Euroisotope/Cambridge Isotope Laboratories (deuterated CAP, D5-CAP, >98 \%). For the evaporation of solvents TurboVap LVTM and TurboVap IITM stations (Zymarck, United States) were used.

An Agilent 5973N mass spectrometer coupled with a GC (HP 6890 plus) and equipped with an automatic sampler (HP 7683) was used for the measurements. The mass spectrometer was operated in the negative ion chemical ionisation mode $(\mathrm{NCl}$ with methane) with the following ions for confirmatory purposes: $\mathrm{m} / \mathrm{z} 466,468,470$, 376 (CAP), 466, 468 (meta-CAP), 471 D5-CAP.

$2 \mu \mathrm{l}$ of the sample are injected splitless into the GC. The separation is performed on a $30 \mathrm{~m}$ * $0.25 \mathrm{~mm}$ id column, $0.25 \mu \mathrm{m}$ ZB5 (Phenomenex) using a flow rate of 1 $\mathrm{ml} / \mathrm{min}$ (Helium 5.0) and the following temperature programme: $85^{\circ} \mathrm{C}(0.1 \mathrm{~min})$; $12^{\circ} \mathrm{C} / \mathrm{min}$ to $240^{\circ} \mathrm{C} ; 5^{\circ} \mathrm{C} / \mathrm{min}$ to $260^{\circ} \mathrm{C} / \mathrm{min}$; $\quad 15^{\circ} \mathrm{C} / \mathrm{min}$ to $290^{\circ} \mathrm{C}$ (5 min hold). The injection block is operated at $280^{\circ} \mathrm{C}$, the transfer line at $290^{\circ} \mathrm{C}$ and the ion source at $160{ }^{\circ} \mathrm{C}$.

\section{Sample preparation}

Freeze-dried laboratory sample $(2 \mathrm{~g})$ was reconstituted with water to the original fresh sample weight $(10 \mathrm{~g})$. The internal standard (CAP-D5) was added to the sample followed by $20 \mathrm{ml}$ of an extraction mixture (acetonitrile / $4 \% \mathrm{NaCl}$ in water solution $1+1 \mathrm{~V}+\mathrm{V}$ ). The mixture was homogenised in a stomacher (Seward, United Kingdom) and transferred into a centrifuge tube. The stomacher bag was rinsed twice with $4 \mathrm{ml}$ of an extraction mixture, the solution was added to the centrifuge tube and centrifuged (4000 rpm for $15 \mathrm{~min}$ ). The supernatant was separated and de-fatted twice with $10 \mathrm{ml}$ of $\mathrm{n}$-hexane. Water-saturated ethyl acetate $(7 \mathrm{~mL})$ was added to the remains, the mixture vortexed and the supernatant was transferred to a TurboVap 
tube. This extraction procedure with ethyl acetate was repeated. The combined supernatants were evaporated to dryness and re-dissolved in $3 \mathrm{ml}$ of water/acetonitrile $(95+5 \mathrm{~V}+\mathrm{V})$. The re-dissolved sample was applied onto a C18 cartridge (500 mg, Separtis, Switzerland, preconditioned with $10 \mathrm{ml}$ of methanol and $10 \mathrm{ml}$ of water/acetonitrile $(95+5 \mathrm{~V}+\mathrm{V})$. The sample was eluted with $3 \mathrm{ml}$ of water/acetonitrile $(45+55 \mathrm{~V}+\mathrm{V})$. Water-saturated ethyl acetate $(4 \mathrm{ml})$ was added to the eluted sample, the mixture vortexed and the supernatant separated. This extraction procedure was repeated. The combined extracts were evaporated to dryness under a nitrogen stream. The dry residue was re-dissolved in $1 \mathrm{ml}$ of acetone/toluene $(20+80 \mathrm{~V}+\mathrm{V})$ and then applied onto a Silica cartridge $(1 \mathrm{~g}$, Separtis, Switzerland, preconditioned with $6 \mathrm{ml}$ of acetone/toluene $(20+80 \mathrm{~V}+\mathrm{V})$.

The cartridge was washed twice with $3 \mathrm{ml}$ of acetone/toluene $(20+80 \mathrm{~V}+\mathrm{V})$ and the sample was eluted into a derivatisation tube with $6 \mathrm{ml}$ of acetone/toluene $(70+30$ $\mathrm{V}+\mathrm{V})$. The extract was evaporated to dryness. $50 \mu$ l of the derivatisation mixture N,Obis (trimethylsilyl)acetamide $(\mathrm{BSA}) / \mathrm{n}$-heptane $(1+1 \mathrm{~V}+\mathrm{V})$ were added to the dry extract. The derivatisation tubes were closed carefully and set aside to react for approx. $45 \mathrm{~min}$ at $60^{\circ} \mathrm{C}$. The amount of $2 \mu \mathrm{l}$ of the mixture was directly injected into the GC-MS system.

\section{Validation and validation data}

The validation of the method was carried out according to the alternative validation model suggested in Commission Decision 2002/657 ("in-house validation approach"). This model is based on an experimental plan, which was created by means of the validation software InterValTM. In the validation study, 16 different factor-levelcombinations (using 16 different matrices) were tested. The following factors were 
varied during the validation on two levels each: species (as a leading factor), operator, cartridge lots, storage times of the extracts, sample amount, extraction and centrifugation conditions. The resulting experimental plan is given in table 1 . In order to get reliable validation data, it is required that firstly, for each of the runs a different matrix is used, and secondly, the experiments are carried out at different times (not more than one or two runs at a time). This study was carried out within 10 weeks.

[Insert table 1 about here]

For each of the 16 factor level combinations, five analysis were carried out (blank material was spiked at levels of $0.05,0.08,0.12$ and $0.2 \mathrm{ng} / \mathrm{g}$ and a blank with only internal standard); i.e. a total of 80 analyses was carried out. The resulting concentrations were calculated by using a standard calibration curve. The results of these analyses are shown in figure 1. The figure gives the 16 "calibration curves" for the different factor level combinations as well as the prediction interval.

[Insert figure 1 about here]

From these data, the method validation characteristics are calculated. The data are summarised in table 2.

[Insert table 2 about here]

Furthermore, it is possible to estimate the contributions of the selected factors and the uncertainty due to the matrix/run deviations to the total uncertainty of the result. Details can be found e.g. described by Uhlig et al. (2003). 
[Insert figure 2a,b about here]

\section{Incurred material}

\section{Production of proficiency test samples}

Incurred material was provided by a German import control point. This material consisted of non-compliant samples, remainders of import control tests. There were three different types of material, two from shrimps and one from crayfish (see table 3). The samples were frozen and homogenised when they arrived in the laboratory. The samples were pre-tested for their CAP content, subsequently freeze-dried and the water content was calculated. The lyophilised material was homogenised in a Grindomix mixer (Retsch, Germany) and in an overhead rotary tumbler for two days. Two of the samples were used directly in this form. The third sample was diluted with blank material (obtained from the grocery, tested for compliance prior to use) in order to achieve more relevant residue levels. The preparation of the proficiency test samples targeted at concentration levels close to the MRPL-level of $0.3 \mu \mathrm{g} / \mathrm{kg}$.

[Insert table 3 about here]

The material was portioned and filled into dark glass vials, each with a quantity of approximately $4 \mathrm{~g}$. Although the water content was different for the different materials (60 to $88 \%$ ), a joint value of $80 \%$ was given in order to avoid the possibility of identifying the samples by their water content. So each portion of lyophilised material referred to a theoretical amount of approximately $20 \mathrm{~g}$ of fresh sample. After having 
packed the samples, the dark glass vials are labelled with randomised sample codes (prepared by using the software "ProlabTM").

Approximately 100 aliquots of each of the samples were available. Five samples each were combined in a set of samples. The sets contained, as shown in table 3 , one blank sample (CAP004) and four non-compliant samples (CAP001,-002,-003,005). One of the non-compliant samples was sent in duplicate, but without indicating this fact to the participants, in order to be able to check the repeatability of the measurements (CAP002/CAP005).

\section{Homogeneity and stability}

For testing homogeneity, 10 randomly selected aliquots of each sample (prior to combining it in test sets) were analysed in duplicate using the method described above. The results were evaluated by analysing variance and by comparing the standard deviation occurring between different aliquots $S_{S}$ with the Horwitz standard deviation $\mathrm{S}_{\mathrm{H}}$. It turned out that all samples belonged to the same population and had a ratio $S_{S} / S_{H}<0.3$ as requested in the IHPPT, see table 4.

[Insert table 4 about here]

For stability testing, the samples were stored under different conditions $\left(-80^{\circ} \mathrm{C}\right.$, $30^{\circ} \mathrm{C},+4^{\circ} \mathrm{C},+20^{\circ} \mathrm{C}$ ) and analysed after storage periods of one day to one year. The storage of aliquots at $+20^{\circ} \mathrm{C}$ was stopped after one month since this storage condition was primarily chosen to prove the stability of the samples during shipping and sample handling (and due to the limited number of available samples for stability testing). For each of the storage time/storage condition combinations, two aliquots 
were randomly selected. Each aliquot was analysed in double. The use of an isochronous approach as suggested by Linsinger et al. (2004) was not suitable for this study, because in this connection, two significant disadvantages would come into effect: great number of samples to be analysed at one time and the results not being available until the very end of the stability study. Hence, as a compromise, the tests were performed using a „semi-isochronous“ approach. Analysis was done after three different periods of time ( 2 days, 1 month, 1 year), so that, on the one hand, an acceptable number of samples has be analysed at a time and, on the other hand, stability data which were sufficient to start the proficiency test were already available after one month. In the stability study, no degradation of the analyte could be observed as can be seen in figure 3.

[Insert figure 3 about here]

\section{Proficiency test}

The proficiency test started in November 2004 with the shipment of the samples. The frozen samples $\left(-20^{\circ} \mathrm{C}\right)$ were shipped without dry-ice because even at room temperature the material proved to be stable for some weeks (see figure 3). Each laboratory received a set of five samples. The samples should be analysed with the method routinely applied (a confirmatory method according to Commission Decision 2002/657EC) and results submitted within six weeks.

\section{Evaluation}

The proficiency test was organised and evaluated according to the prescriptions of the IHPPT, ISO/IEC-Guide 43-1: 1977 and DIN 38402-45: 2003-09 using the 
statistical software "ProlabTM" (quo data Ltd. Dresden, Germany). The z-scores for the laboratories' quantitative results were calculated from the laboratory results $x$, the target value $X$ (here: consensus value of all submitted results) and the target value of the standard deviation $\sigma$.

$$
\text { z-score }=\frac{x-X}{\sigma}
$$
x : laboratory result
$\mathrm{X}$ : target value
$\sigma: \quad$ target value of the standard deviation

The laboratories were asked to analyse the samples in double each and to submit the recovery corrected results. The mean value of these determinations was used and taken as the laboratory result $(\mathrm{x})$ without any further correction.

The target value $\mathrm{X}$ was determined by calculating the median of the results of all laboratories (consensus value). The National Reference Laboratory; Berlin, took part in the study as one of the laboratories. As target value of the standard deviation, the reproducibility standard deviation was calculated using the Q-method as described in DIN 38402-45. The reproducibility standard deviation was taken instead of the Horwitz standard deviation (Horwitz et al. 1980, Boyer et al. 1985) because at these low concentrations, the latter would allow significantly higher standard deviations and considerably limit the significance of the quantitative assessment of the proficiency test.

In addition to the individual quantitative assessment of each sample, the NRL uses a point system with the purpose of evaluating the overall proficiency of the laboratories. In order to take into account not only the quantitative but also the qualitative 
evaluation (especially meaningful for banned substances as CAP), the following rules within a point system were applied:

\author{
z-scores: $\quad \mid z$-score $\mid>2$ : (qualitative detection is carried out, $\quad+1.0$ point \\ quantification outside tolerance limits) \\ $\mid z$-score $\mid>2$ : (qualitative detection is carried out, \\ +1.5 points \\ quantification within tolerance limits) \\ false positive results: \\ -1 point \\ false negative results: \\ 0 points
}

This system is applied per analyte and per sample, i.e. in this case, there are a maximum of six attainable points $(4 * 1.5)$. The minimum score for passing this proficiency test was set at 4.0 points (corresponding to $66.7 \%$ of the maximum score). The score for banned compounds is generally set in such a manner that it is possible to be successful in the overall proficiency by simply identifying the banned compound (which is, in principle, sufficient), if there are no false positive findings in the blank samples.

\title{
Results and discussion
}

A total of 20 participants submitted results. For each sample, the median was calculated as a target value, including all results into the calculation (no outlier elimination). No false negative results and only one false positive result were reported for a total of 100 analyses. For the quantitative evaluation on the basis of zscores, the reproducibility standard deviation was used, the results and the used techniques are summarised in figure 4. Four of the results (from three different labs, 
but from one matrix, namely CAP002/CAP005) lay outside the range of $+/-2$, nevertheless three of these four results were close to a z-score of 2.

[Insert figure 4 about here]

In contrast to the other samples, this matrix was a processed food sample. With the method applied by the NRL, an unusual behaviour during the extraction process (problems in phase separation) was observable. The difficulties with this sample are also reflected in the results of the proficiency test (results out of the z-scores and high reproducibility standard deviations for GC methods)).

[Insert table 5 about here]

The Horrat ratio (see table 5), which gives a certain indication of the overall performance level of the laboratories, should be between 0.5 to 2 for acceptable method performance as suggested by Pocklington 1990. The ratio here is even below 0.5 , indicating a very good performance of the laboratories.

The evaluation of the overall proficiency based on the point system (see above) added up to a mean of 5.85 points (out of six attainable points, referring to $97.5 \%$ ), all laboratories have been successful.

The participants were asked to provide details of their analytical method. The results were also evaluated with respect to this additional information. The very different sample clean-ups (extraction with different solvents; clean-up with solid phase extraction, liquid-liquid extraction, silica clean-up, or a combination thereof) as well as a hydrolysis step, which was included by some of the laboratories, did not have any significant effect on the results. Most of the laboratories used deuterated CAP as the 
internal standard. Meta-CAP was used only in three laboratories as the internal standard all of them applied GC-methods. The use of meta-CAP as an internal standard showed a tendency towards a higher scatter of the results but this conclusion is uncertain because of the very small number of measurements.

The only parameter which showed a bias was the comparison of GC/MS(MS) and LC/MSMS results (see table 6). GC/MS results showed a tendency towards higher concentration levels with a worse reproducibility compared to the LCMSMS results.

[Insert table 6 about here]

This effect would be similar, if the results of the two labs, which applied GC/MSMS, would be treated separately. An explanation of this effect is difficult due to the principle difference between the methods, e.g. the different ionisation mechanism, the necessary derivatisation for GC analysis and the different selectivity of the detection systems. Further studies using certified reference material would be necessary in order to verify whether there is a bias between the two techniques or whether it is just a matrix dependent effect.

All in all, the results of the study were very positive. The median concentrations were between 0.43 and $0.51 \mu \mathrm{g} / \mathrm{kg}$ CAP, the reproducibility ranged from 17 to $24 \%$ (clearly below the Horwitz standard deviation of about $50 \%$ ). None of the laboratories found false negative samples.

A conclusion of the results of the study is that the analysis of CAP residues is well established in many labs and the decision limits between 0.05 and $0.36 \mathrm{ng} / \mathrm{g}$, indicated by the labs, were realistic because all labs were successful in confirming the analytes in the non-compliant samples. Accordingly the methods tested in the 
study, including the one used by the NRL, proved to be suitable for the control of residue levels around the MRPL of $0.3 \mu \mathrm{g} / \mathrm{kg}$. 


\section{References:}

Boyer KW, Horwitz W, Albert A. 1985. Interlaboratory variability in trace elements analysis. Anal. Chem. 57:454-459.

Commission Decision 2002/657/EC of 12 August 2002 implementing Council Directive 96/23/EC concerning the performance of analytical methods and the interpretation of results. Official Journal L 221: 8.

Commission Decision 2003/181/EC of 13 March 2003 amending Decision $2002 / 657 / E C$ as regards the setting of minimum required performance limits (MRPLs) for certain residues in food of animal origin (Text with EEA relevance) (notified under document number C(2003) 764) Official Journal L 071:17 - 18

Council Directive 96/23/EC of 29 April 1996 on measures to monitor certain substances and residues thereof in live animals and animal products and repealing Directives 85/358/EEC and 86/469/EEC and Decisions 89/187/EEC and 91/664/EEC. Official Journal L 125:10.

Council Regulation (EC) No. 882/2004 of the European Parliament and of the Council of 29 April 2004 on official controls performed to ensure the verification of compliance with feed and food law, animal health and animal welfare rules. Official Journal L 165:1.

Council Regulation (EEC) No. 2377/90 laying down the procedure for the establishment of minimum residue levels (MRLs) of veterinary medicinal products of food stuffs of animal origin. Official Journal L 224: 1 .

DIN 38402-45. 2002. "Deutsche Einheitsverfahren zur Wasser-, Abwasser- und Schlammuntersuchung; Allgemeine Angaben (Gruppe A) - Part 45: Ringversuche zur externen Qualitätskontrolle von Laboratorien" ("German standardised procedures for the analysis of water, sewage and sludge; general information (group A) - part 42- ring tests on the external quality control of laboratories" (April 2002)) 
Hammack W, Carson MC, Neuhaus BK. 2003. Multilaboratory validation of a method to confirm chloramphenicol in shrimp and crabmeat by liquid chromatographytandem mass spectrometry. Journal of AOAC International 86: 1135-1143.

Horwitz W, Kamps LR, Boyer KW. 1980. Quality assurance in the analysis of foods for trace constituents. J. Assoc. Off. Anal. Chem. 63:1344-1354.

ISO/IEC Guide 43-1.1997. Proficiency testing by interlaboratory comparisons - Part 1: Development and operation of proficiency testing schemes. Genf, Schweiz.

Jülicher B, Gowik P, Uhlig S. 1998. Assessment of detection methods in trace analysis by means of a statistically based in-house validation concept. Analyst 123: 173-179.

Linsinger TPJ, van der Veen AMH, Gawlik BM, Pauwels J, Lamberty A. 2004. Planning and combining of isochronous stability studies of CRMs. Accred. Qual. Assur. 9:464-472.

Mottier P, Parisod V, Gremaud E. 2003. Determination of the antibiotic chloramphenicol in meat and seafood products by liquid chromatography electrospray ionization tandem mass spectrometry. Journal of Chromatography A 994: 75-84.

Peng T, Li S, Chu XG. 2005. Simultaneous determination of residues of chloramphenicol, thiamphenicol and florfenicol in shrimp by high performance liquid chromatography-tandem mass spectrometry. Chinese Journal of analytical chemistry 33: 463-466.

Penney L, Smith A, Coates B. 2005. Determination of chloramphenicol residues in milk, eggs, and tissues by liquid chromatography/mass spectrometry. Journal of AOAC International 88 : 645-653.

Pocklington WD. 1990. Harmonised protocols for the adaoption of standardised analytical methods and for the presentation of their performance characteristics. Pure and Appl. Chem. 62:149-162. 
Ramos M, Munoz P, Aranda A. 2003.Determination of chloramphenicol residues in shrimps by liquid chromatography-mass spectrometry. Journal of Chromatography $B$ 791: 31-38.

Rupp HS, Stuart JS, Hurlbut JA. 2005. Liquid chromatography/tandem mass spectrometry analysis of chloramphenicol in cooked crab meat. Journal of AOAC International $88: 1155-1159$.

Santos L, Barbosa J, Castilho MC. 2005. Determination of chloramphenicol residues in rainbow trouts by gas chromatography-mass spectometry and liquid chromatography-tandem mass spectrometry. Anal. Chim. Acta 529: 249-256.

Thompson M, Wood R. 1993. International Harmonised Protocol for the Proficiency Testing of (Chemical) Analytical Laboratories. Pure and Appl. Chem. 65: 2123 2144.

Uhlig S, Gowik P, Radeck W. 2003. Performance of a matrix comprehensive inhouse validation study by means of an especially designed software, Analytica Chimica Acta 483:351-362. 


\section{Table captions:}

Table 1: Experimental plan for the in-house validation

Table 2: Method performance characteristics

Table 3: Matrix information of test kit submitted to the participants and sample codes

Table 4: Results of homogeneity tests

Table 5: Median, Horrat ratio, repeatability and Horwitz standard deviation $\left(\mathrm{S}_{\mathrm{R}}\right.$ and $\mathrm{S}_{\mathrm{H}}$ of the individual samples

Table 6: Median and repeatability standard deviation (separate calculation for the different systems applied) 


\section{Tables:}

Table 1: Experimental plan for the in-house validation

\begin{tabular}{|c|c|c|c|c|c|c|c|c|}
\hline run & species & operator & $\begin{array}{c}\text { cartridge } \\
\text { lot }\end{array}$ & $\begin{array}{c}\text { test } \\
\text { sample }\end{array}$ & $\begin{array}{c}\text { storage of } \\
\text { extracts }\end{array}$ & centrifugation & extraction & elution \\
\hline$\overline{S \_16}$ & pig & $\bar{B}$ & $\bar{Y}$ & $15 \mathrm{~g}$ & 2-3 days & with $4000 \mathrm{rpm}$ & with $2^{*} 8 \mathrm{ml}$ & $60 / 40 \mathrm{ACN} /$ water \\
\hline S_06 & crustaceans & B & $x$ & $15 \mathrm{~g}$ & 2-3 days & with 3000 rpm & with $2 * 10 \mathrm{ml}$ & 50/50 ACN/water \\
\hline S_01 & crustaceans & A & $x$ & $10 \mathrm{~g}$ & 0-1 day & with 3000 rpm & with 2 * $8 \mathrm{ml}$ & 50/50 ACN/water \\
\hline S_10 & pig & A & $x$ & $15 \mathrm{~g}$ & 2-3 days & with 3000 rpm & with $2{ }^{*} 10 \mathrm{ml}$ & $60 / 40 \mathrm{ACN} /$ water \\
\hline S_12 & pig & A & Y & $15 \mathrm{~g}$ & 0-1 day & with 3000 rpm & with 2 * $8 \mathrm{ml}$ & $50 / 50 \mathrm{ACN} /$ water \\
\hline S_09 & pig & A & $x$ & $10 \mathrm{~g}$ & 2-3 days & with $4000 \mathrm{rpm}$ & with 2 * $8 \mathrm{ml}$ & 50/50 ACN/water \\
\hline S_14 & pig & B & $\mathrm{X}$ & $15 \mathrm{~g}$ & $0-1$ day & with 4000 rpm & with $2 * 10 \mathrm{ml}$ & $50 / 50 \mathrm{ACN} /$ water \\
\hline S_15 & pig & B & Y & $10 \mathrm{~g}$ & $2-3$ days & with 3000 rpm & with $2 * 10 \mathrm{ml}$ & $50 / 50 \mathrm{ACN} /$ water \\
\hline S_04 & crustaceans & A & $\mathrm{Y}$ & $15 \mathrm{~g}$ & 2-3 days & with $4000 \mathrm{rpm}$ & with $2{ }^{*} 8 \mathrm{ml}$ & 50/50 ACN/water \\
\hline S_02 & crustaceans & $A$ & $\mathrm{X}$ & $15 \mathrm{~g}$ & 0-1 day & with $4000 \mathrm{rpm}$ & with $2{ }^{*} 10 \mathrm{ml}$ & $60 / 40 \mathrm{ACN} /$ water \\
\hline$S_{-}^{-} 11$ & pig & A & $\mathrm{Y}$ & $10 \mathrm{~g}$ & $0-1$ day & with $4000 \mathrm{rpm}$ & with $2 * 10 \mathrm{ml}$ & $60 / 40 \mathrm{ACN} /$ water \\
\hline S_03 & crustaceans & A & Y & $10 \mathrm{~g}$ & 2-3 days & with 3000 rpm & with $2 * 10 \mathrm{ml}$ & $60 / 40 \mathrm{ACN} /$ water \\
\hline S_08 & crustaceans & B & Y & $15 \mathrm{~g}$ & 0-1 day & with 3000 rpm & with 2 * $8 \mathrm{ml}$ & $60 / 40 \mathrm{ACN} /$ water \\
\hline S_13 & pig & B & $\mathrm{X}$ & $10 \mathrm{~g}$ & 0-1 day & with 3000 rpm & with $2{ }^{*} 8 \mathrm{ml}$ & $60 / 40 \mathrm{ACN} /$ water \\
\hline S_05 & crustaceans & B & $x$ & $10 \mathrm{~g}$ & 2-3 days & with $4000 \mathrm{rpm}$ & with 2 * $8 \mathrm{ml}$ & $60 / 40 \mathrm{ACN} /$ water \\
\hline S_07 & crustaceans & B & Y & $10 \mathrm{~g}$ & $0-1$ day & with $4000 \mathrm{rpm}$ & with $2 * 10 \mathrm{ml}$ & 50/50 ACN/water \\
\hline
\end{tabular}

Table 2. Method performance characteristics

\begin{tabular}{|l|l|}
\hline Decision limit $\mathrm{CC}_{\alpha}$ & $0.074 \mu \mathrm{g} / \mathrm{kg}$ \\
\hline Detection capability $\mathrm{CC}_{\beta}$ & $0.087 \mu \mathrm{g} / \mathrm{kg}$ \\
\hline Recovery* & $95 \%$ \\
\hline Repeatability*: & $8 \%$ \\
\hline Within-laboratory reproducibility*: & $9 \%$. \\
\hline
\end{tabular}

$\left.{ }^{*}\right)$ at the concentration of $\mathrm{CC}_{\beta}$ 
Table 3: Matrix information of test kit submitted to the participants and sample codes

\begin{tabular}{cl}
\hline Sample code & \multicolumn{1}{c}{ Kind of sample } \\
\hline CAP 001 & CraYfish; non-compliant import sample, Asia \\
CAP 002 & Shrimps, salted, non-compliant import sample, Asia \\
CAP 003 & Prawns, non-compliant import sample; diluted with \\
& blank material, Asia \\
CAP 004 & Polar sea shrimps, blank \\
CAP 005 & As CAP 002 \\
\hline
\end{tabular}

Table 4: Results of homogeneity tests

\begin{tabular}{ccccccc}
\hline Sample & $\begin{array}{c}\text { Test } \\
\text { statistic } \mathbf{F}\end{array}$ & $\begin{array}{c}\text { Critical F- } \\
\text { value }\end{array}$ & Mean $[\boldsymbol{\mu g} / \mathbf{k g}]$ & $\mathbf{s}_{\mathbf{S}}$ & $\mathbf{s}_{\mathbf{H}}$ & $\mathbf{s}_{\mathbf{S}} / \mathbf{s}_{\mathbf{H}}$ \\
\hline CAP 001 & 1.876 & 3.020 & 0.452 & 0.011 & 0.230 & 0.05 \\
CAP 002/5 & 1.227 & 3.020 & 0.460 & 0.015 & 0.234 & 0.06 \\
CAP 003 & 1.578 & 3.020 & 0.356 & 0.048 & 0.188 & 0.26 \\
\hline
\end{tabular}

$S_{S}:$ Standard deviation between different samples $(n=10)$

$S_{H}$ : Horwitz standard deviation at the respective concentration 
Table 5: Median, Horrat ratio, repeatability and Horwitz standard deviation $\left(\mathrm{S}_{\mathrm{R}}\right.$ and $\mathrm{S}_{\mathrm{H}}$ of the individual samples

\begin{tabular}{lcccccc}
\hline Sample & Median & $\begin{array}{c}\text { Horrat } \\
\text { ratio }\end{array}$ & \multicolumn{2}{c}{$\mathbf{s}_{\mathbf{R}}$} & \multicolumn{2}{c}{$\mathbf{s}_{\mathbf{H}}$} \\
& {$[\boldsymbol{\mu g} / \mathbf{k g}]$} & $\mathbf{s}_{\mathbf{R}} / \mathbf{s}_{\mathbf{H}}$ & abs. & $\%$ & abs. & $\%$ \\
\hline CAP 001 & 0.512 & 0.49 & 0.124 & 24.3 & 0.256 & 50.0 \\
CAP 002 & 0.500 & 0.37 & 0.093 & 18.6 & 0.251 & 50.2 \\
CAP 003 & 0.427 & 0.34 & 0.073 & 17.0 & 0.219 & 51.4 \\
CAP 005 & 0.491 & 0.43 & 0.107 & 21.7 & 0.247 & 50.4 \\
\hline
\end{tabular}

Table 6: Median and repeatability standard deviation (separate calculation for the different systems applied)

\begin{tabular}{|c|c|c|c|c|}
\hline \multirow[t]{2}{*}{ Sample } & \multicolumn{2}{|c|}{$\begin{array}{l}\text { GC-MS (including GC-MS/MS) } \\
\qquad n=10(n=2)\end{array}$} & \multicolumn{2}{|c|}{$\begin{array}{c}\text { LC-MS/MS } \\
n=10\end{array}$} \\
\hline & $\begin{array}{l}\text { Median } \\
{[\mu \mathrm{g} / \mathrm{kg}]}\end{array}$ & $\mathbf{S}_{\mathbf{R}}$ & $\begin{array}{l}\text { Median } \\
{[\mu \mathrm{g} / \mathrm{kg}]}\end{array}$ & \\
\hline CAP001 & 0.619 & $0.133=21.5 \%$ & 0.477 & $0.101=21.2 \%$ \\
\hline CAP002 & 0.525 & $0.128=24.4 \%$ & 0.469 & $0.075=16.9 \%$ \\
\hline CAP003 & 0.425 & $0.090=21.2 \%$ & 0.427 & $0.067=15.7 \%$ \\
\hline CAP005 & 0.503 & $0.155=30.8 \%$ & 0.486 & $0.067=13.8 \%$ \\
\hline
\end{tabular}




\section{Figure captions:}

Figure 1: Confidence interval of the 16 calibration curves calculated from the 16 different runs (factor-level-combinations) according to table 1.

Figure $2 \mathrm{a}$ and $2 \mathrm{~b}$ : Matrix blank (2a) and spiked matrix blank (2b) in crustaceans, spike level at $0.08 \mathrm{ng} / \mathrm{g}(\mathrm{m} / \mathrm{z} 471$ referring to the internal standard, the other ion traces to CAP)

Figure 3: Results of the degradation study (CAP_002), concentration in ng/g

Figure 4: Summary of the $z$-scores of the participating laboratories (dark triangles indicating results out of the accepted tolerance of $+/-2$ ) 
Figures:

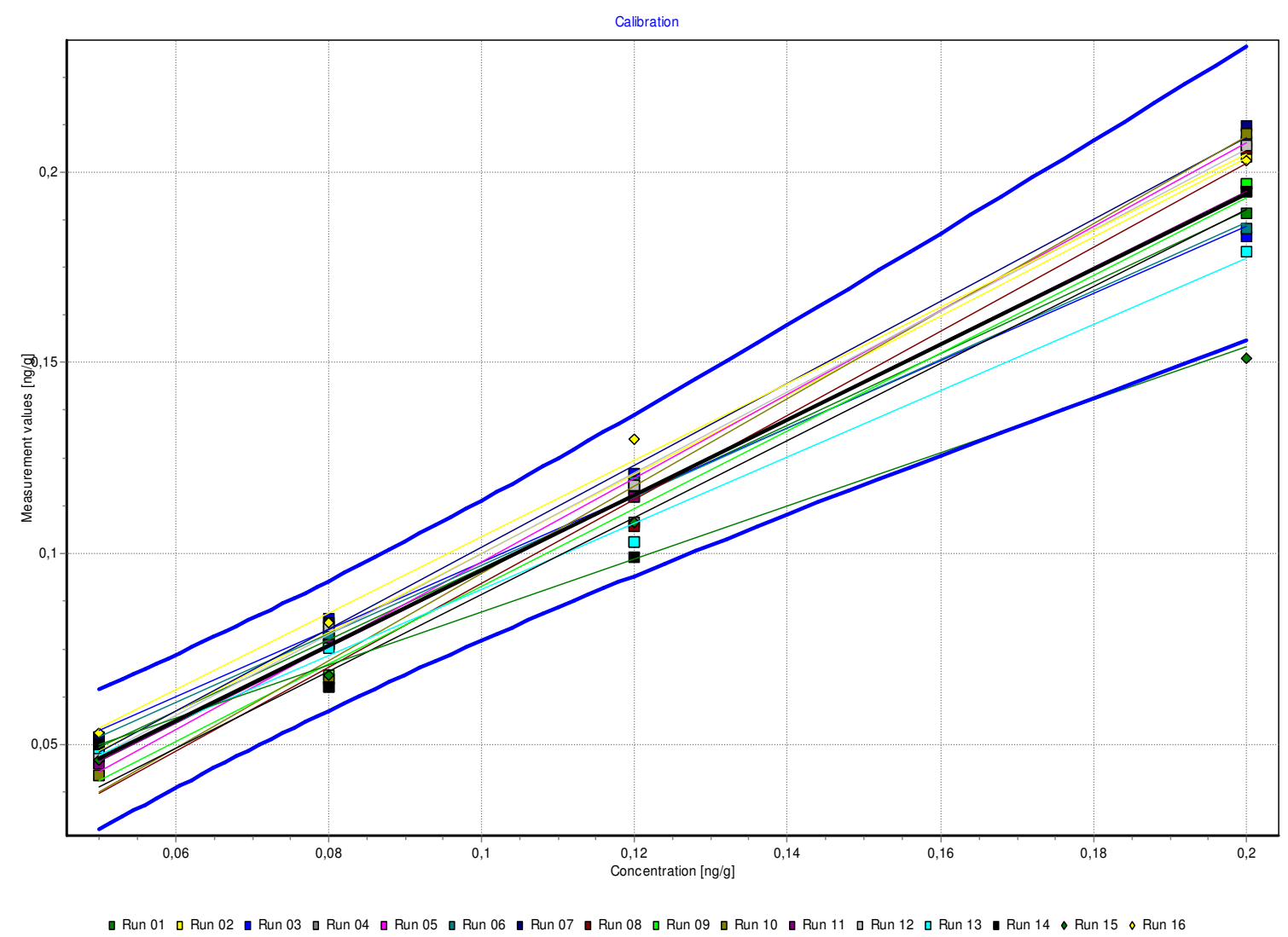

Figure 1: Confidence interval of the 16 calibration curves calculated from the 16 different runs (factor-level-combinations) according to table 1. 


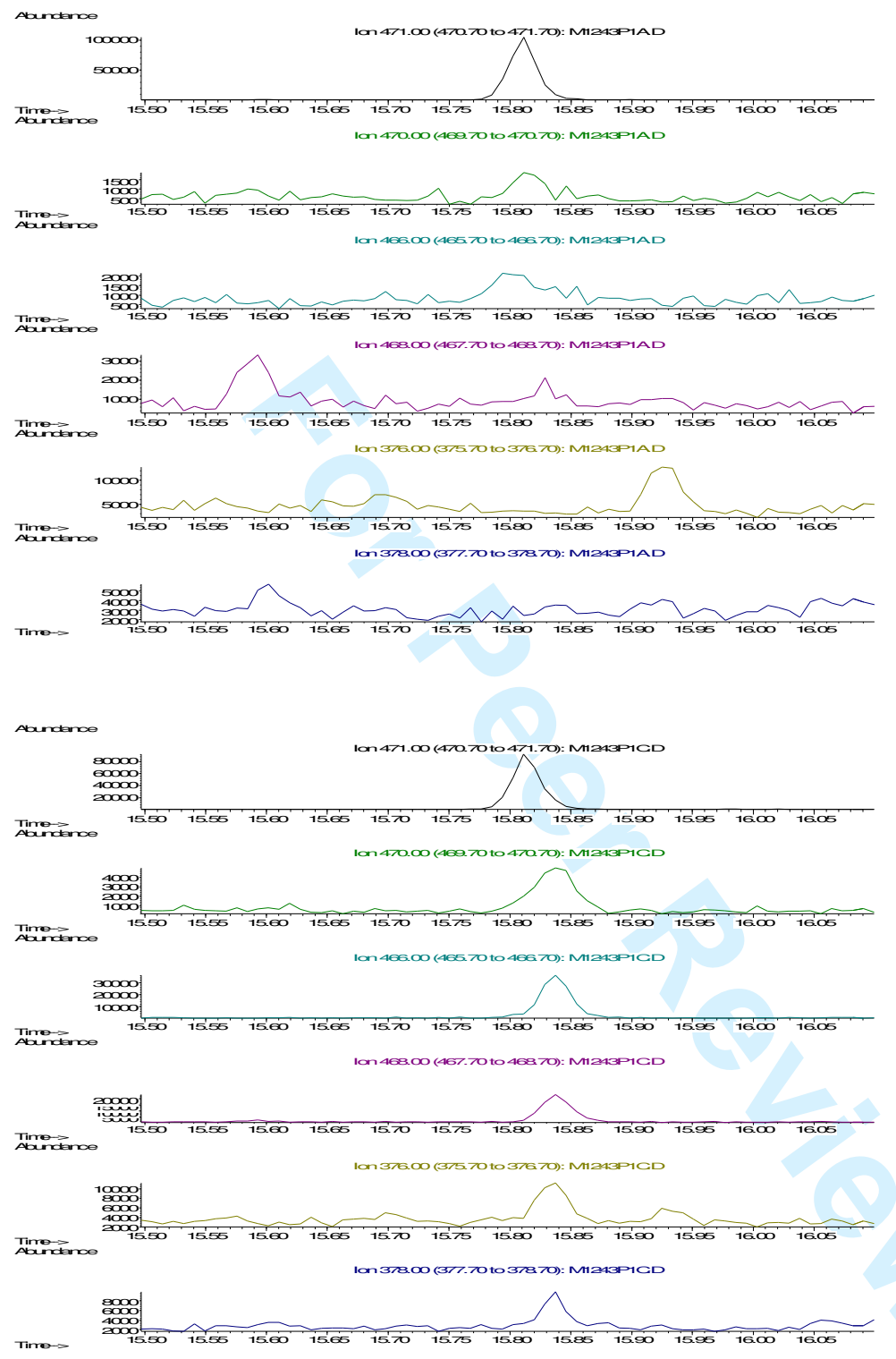

Figure $2 \mathrm{a}$ and $2 \mathrm{~b}$ : Matrix blank (2a) and spiked matrix blank (2b) in crustaceans, spike level at $0.08 \mathrm{ng} / \mathrm{g}(\mathrm{m} / \mathrm{z} 471$ referring to the internal standard, the other ion traces to CAP) 


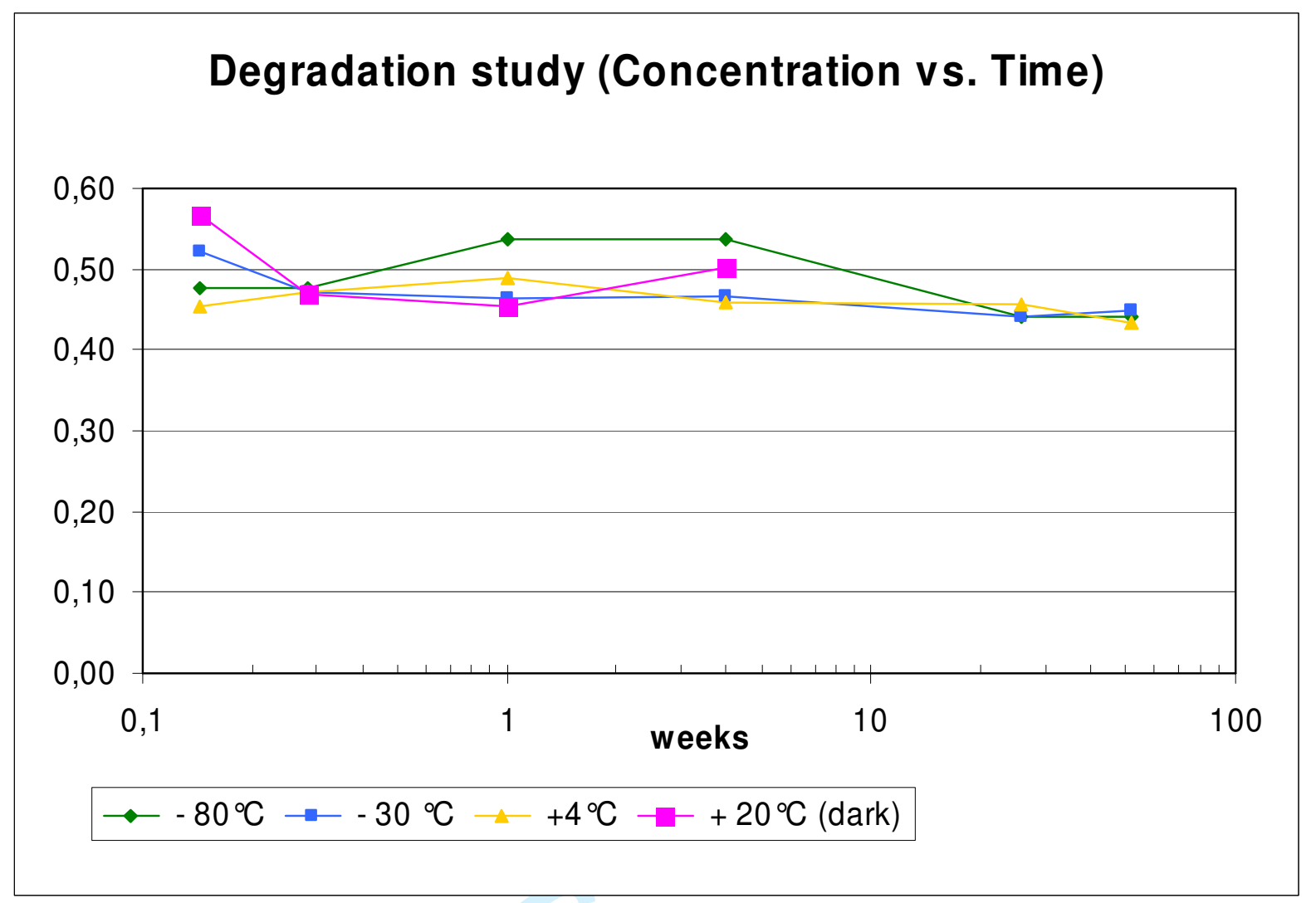

Figure 3: Results of the degradation study (CAP_002), concentration in ng/g 
Figure 4: Summary of the z-scores of the participating laboratories (dark triangles indicating results out of the accepted tolerance of $+/-2$ ) 